\title{
Multimodal Characterization of Population Responses Evoked by Applied Electric Field in vitro: Extracellular Potential, Magnetic Evoked Field, Transmembrane Potential, and Current-Source Density Analysis
}

\author{
Luisa Lopez, ${ }^{1}$ Christopher Y. Chan, ${ }^{2}$ Yoshio C. Okada, ${ }^{3}$ and Charles Nicholson ${ }^{1}$ \\ 'Department of Physiology and Biophysics, New York University Medical Center, New York, New York 10016, \\ 2Department of Physiology, CUNY Medical School, New York, New York 10031, and '3Departments of Neurology and \\ Physiology, University of New Mexico School of Medicine and Center for MEG, VA Medical Center, Albuquerque, New \\ Mexico 87108
}

An external electric field applied parallel to longitudinal axis of neurons selectively depolarizes either end and thereby activates voltage-sensitive conductance changes in a large population of neurons. Here, we characterized such population responses in the in vitro turtle cerebellum. The responses were recorded and analyzed using a multimodal approach: the magnetic evoked field was measured using a Superconducting Quantum Interference Device (SQUID) magnetometer, and concurrently the electric field potentials were recorded. Laminar profile and current-source density analysis were used to uncover the pattern of activation due to the applied electric field. Intracellular recording provided further information for identifying the elements producing the observed responses. Finally, pharmacological manipulations confirmed the nature of the conductance changes.

Our results show that it is possible to activate a defined cell population of the cerebellum by an applied field and obtain a magnetic response of the order of 0.5-2 pT. A field applied from the dorsal to the ventral side of cerebellum produced tetrodotoxin-sensitive population spikes. This component was followed by a kynurenic acid (KYNA)-sensitive postsynaptic response, most likely comprised of $\mathrm{Ca}^{2+}$ mediated action potentials occurring at the proximal pole of the Purkinje cell dendrites and evoked by climbing fiber inputs. The applied electric field directed from the ventral to the dorsal side of cerebellum gave rise to a complex of responses that was made up of a KYNA-sensitive component (presumably synaptically activated) and an $\mathrm{Mn}^{2+}$-sensitive but KYNA-insensitive component (probably due to a directly activated calcium conductance change).

This study provides insights into the effects of electric and magnetic fields applied to the nervous tissue of experimental animal and human studies.

Electrophysiology has become increasingly focused on the single cell, but the ultimate goal of this discipline remains the understanding of neuronal circuits. In this study, for the first time,

Received Aug. 31, 1990; revised Jan. 31, 1991; accepted Feb. 5, 1991.

This research was supported by NINDS Grant NS21149 to Y.C.O., CNRNATO (Italy) Fellowship 215.22/11 to L.L., and U.S. Public Health Service Grants 2-S07-RR-7132 to C.Y.C. and NS 13742 to C.N.

Correspondence should be addressed to Yoshio C. Okada, MEG Center (101) Veterans Administration Medical Center, 2100 Ridgecrest Dr., S.E., Albuquerque, NM 87108.

Copyright (C) 1991 Society for Neuroscience $0270-6474 / 91 / 111998-13 \$ 03.00 / 0$ we combined applied electric field stimulation with several powerful methods for the analysis of neuronal population responses, and intracellular recording, to look at neuronal ensembles. We chose the isolated turtle cerebellum for our investigation because this preparation offers unparalleled opportunities to explore an intact 3-D neuronal circuit. Our approach was twofold. First, we activated selected neuronal elements with controlled electric fields that induced precise neuronal polarization. We combined this mode of activation with conventional electrical afferent stimulation. Second, we correlated evoked response modalities by measuring laminar field potentials, current-source densities (CSDs), magnetic evoked fields (MEFs), and transmembrane potentials (TMPs). These measurements were supplemented by appropriate pharmacological dissection of the neuronal circuits. Our results reveal the wealth of information inherent in population responses evoked by applied fields and provide a basis for future detailed analysis.

An electric field applied parallel to the longitudinal axis of a neuron can be used to depolarize or hyperpolarize either pole of the neuron selectively and thereby activate voltage-sensitive conductance changes remote to the recording microelectrode (Chan et al., 1988). The extracellular unit recording (Chan and Nicholson, 1986) and intracellular potential studies (Chan et al., 1988) of neuronal responses produced by an applied electric field revealed the usefulness of this technique in selectively activating various types of voltage-sensitive channels such as lowthreshold $\mathrm{Na}^{+}$and $\mathrm{Na}^{+}$-plateau currents and $\mathrm{Ca}^{2+}$ currents that are segregated in different regions of the Purkinje cell.

A large population of neurons may be activated by the electric field when it is applied to a cortical tissue in which many neuronal processes are uniformly oriented in the direction of the applied field. The synchronized currents associated with such a population response should produce an extracellular ficld potential (EP) as well as an MEF measurable outside the tissue. Such population responses have not been well characterized. We compared these two modalities of evoked response to the underlying neuronal activities that were revealed through laminar potential and CSD analysis and intracellular recording of the TMP of individual Purkinje cells.

The present study used the isolated cerebellum of the turtle, because the geometry of its cellular organization is optimal for the analysis of population responses produced by an applied field. The entire cerebellum is intact in this preparation; thus, its integral circuitry is preserved. The structure of the cerebellum is relatively simple, because the elongated elements are aligned 


\section{MEF measurements}

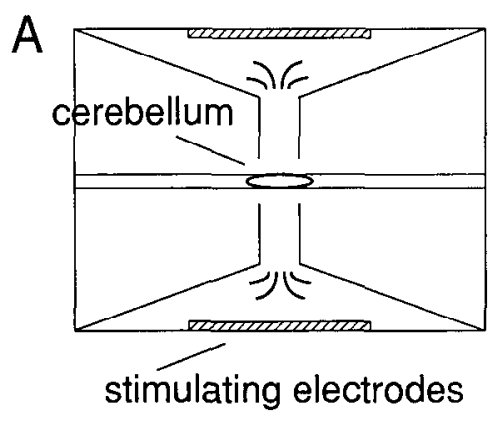

B

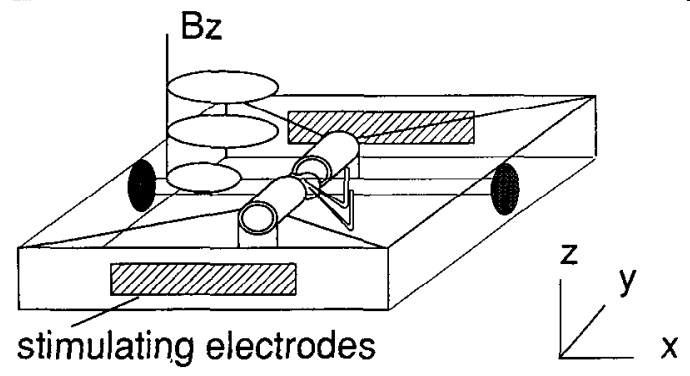

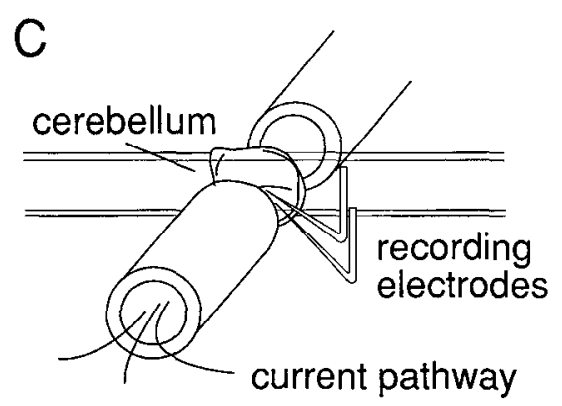

D

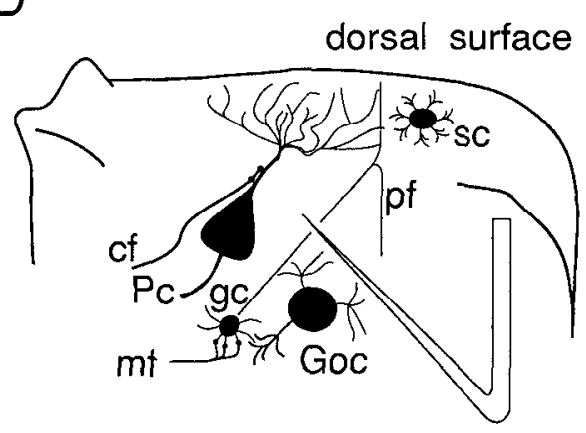

Figure 1. Experimental setup for monitoring EP and MEF responses to applied electric field. $A$, The ccrcbellum was held vertically in a Plexiglas chamber $(14 \times 14 \mathrm{~cm})$. Two stimulating electrodes were placed at opposite ends of the chamber facing the dorsal and ventral cerebellar surfaces. $B$, The chamber was compartmentalized by vertical dividers and connected by cylindrical channels to intensify and focus the current. The SQUID was placed along the rostrocaudal axis (i.e., $\mathrm{x}$-axis) to measure the magnetic field $(B z)$ at the maxima. $C$, Closeup view of the position of the cerebellum, showing its orientation with respect to the channels and the two bent-glass microelectrodes used to record electric field potential. $D$, Schematic representation of the orientation of cerebellar neuronal elements. Note that the Purkinje cell dendrites, climbing fibers, and ascending axons of granule cells are aligned along the $y$-axis, while the parallel fibers lie along the $\mathrm{z}$-axis. $P c$, Purkinje cells; $c f$, climbing fibers; $p f$, parallel fibers; $g c$, granular cells; $m f$, mossy fibers; $s c$, stellate cells; Goc, Golgi cells. along a system of orthogonal axes within a flat ellipsoidal tissue: the dendrites of the Purkinje cells, the ascending axons of granule cells, and the terminal portion of climbing fibers have their longitudinal axes oriented perpendicularly to the surface, that is, along the dorsoventral (d-v) axis; the parallel fibers are located along the mediolateral axis in the molecular layer; and the rostrocaudal axis may contain the horizontal portion of the climbing fibers and mossy fibers in the granular layer. The two excitatory synaptic connections to the Purkinje cells are well separated morphologically: the climbing fiber synapses are in the proximal third of Purkinje cell dendrites, whereas the parallel fiber synapses are in the distal two-thirds (Künzle, 1985; Hounsgaard and Midtgaard, 1989). The inhibitory stellate cells are distributed in the molecular layer. The dendrites of those in the mid-molecular layer have a so-called "closed field" configuration (Lorente de Nó, 1947), but elsewhere they have a bitufted configuration or a ventrodorsal ( $v-d$ ) orientation (Chan and Nicholson, 1986). The cerebellum can be thus oriented so that the dorsoventral axis is parallel to the applied electric field to stimulate its major core conductors.

Two different types of applied field were used in this study. In one case, a brief pulse electric field was applied either from the dorsal to the ventral surface or in the opposite direction. This stimulus was chosen in order to compare the responses with those obtained by local stimulation of the peduncle. Furthermore, the cancellation of the artifact is easier for short stimuli, which are already over when the responses occur. In the other case, an amplitude-modulated, sinusoidal (4-6 Hz), spatially uniform electric field was applied along the dorsoventral axis. The choice of the sine wave was prompted by the fact that the short square wave caused fast transients that were difficult to interpret in terms of the effective direction of polarization of the core conductors. Furthermore, the low-frequency sinusoidal field prevents artifacts due to capacitative properties of the membranes and provides a high degree of synchronization of the population responses.

We have recorded the MEF in order to see to what extent the different types of membrane conductance change may produce magnetic fields. Studies performed on isolated axons (Wikswo et al., 1981) have correlated the MEF with the TMP during the action-current propagation. We have previously used an intact brain structurc, namely, the isolated cerebellum of turtle, to determine the relationship between the MEF and intracellular currents produced by a peduncular stimulation (Okada and Nicholson, 1988; Okada et al., 1989).

Some preliminary results have been previously published (Okada et al., 1988b; Lopez et al., 1989).

\section{Materials and Methods}

Preparation. The turtle, Pseudemys scripta elegans, was decapitated. The cerebellum, which is a shell-like ellipsoidal structure, was dissected from the rest of the brain, and the arachnoid was removed. In the magnetic field recording facility (see below), the cerebellum was placed on edges, supported by a net, in a Plexiglas chamber (Fig. 1), and perfused with Ringer's solution (in mM: $\mathrm{NaCl}, 100 ; \mathrm{KCl}, 5 ; \mathrm{NaHCO}_{3}, 40$; $\mathrm{CaCl}_{2}, 2 ; \mathrm{MgCl}_{2}, 2$; and glucose, 20; equilibrated with $95 \% \mathrm{O}_{2}$ and $5 \%$ $\mathrm{CO}_{2}$ ). For intracellular recordings (Fig. 2), the cerebellum was held horizontally in a different chamber as described previously (Chan and Nicholson, 1986).

Stimulation. Two $\mathrm{Ag} / \mathrm{AgCl}(4 \times 1 \mathrm{~cm})$ plates were placed at the two sides of the magnetic evoked field recording chamber. The current was focused through Plexiglas tubing (3-mm diameter) so that it passed through the cerebellum along the ventrodorsal axis. The transmembrane potential recording chamber also had a similar pair of $\mathrm{Ag} / \mathrm{AgCl}$ plate electrodes placed above and below the horizontal cerebellum (Fig. 2).

Two stimuli were used: square wave $(300-500-\mu \sec$ duration; $2-4$ times the $\mathrm{Na}^{+}$-component threshold amplitude; $0.5-\mathrm{Hz}$ frequency) and sinusoid (2-6 Hz; 2-4 times threshold amplitude).

Recording of the magnetic evoked field. The magnetic evoked field was recorded according to a coordinate system with origin at the center of the cerebellum, at $20 \mathrm{~mm}$ on the z-axis, 13 and $-13 \mathrm{~mm}$ on the $\mathrm{x}$-axis, and $0 \mathrm{~mm}$ on the $\mathrm{y}$-axis (Fig. 1; Okada and Nicholson, 1988). 


\section{TMP measurements}

Figure 2. Experimental setup for monitoring EP and TMP responses to applied electric field (side view). $A$, The cerebellum was placed horizontally between two nylon meshes stretched over a hole in the central partition of the recording chamber. Physiological saline and electrical currents were allowed to pass through the hole. $B$, Positions of the two pairs of recording microelectrodes used to record EP and TMP are shown in relation to the neuronal elements (not drawn to scale). Separate sets of different amplifiers were used to subtract out the sinusoidal artifact. As in Figure 1, electric fields were applied along the $d-v$ axis (i.e., y-axis). Abbreviations are as in Figure 1.
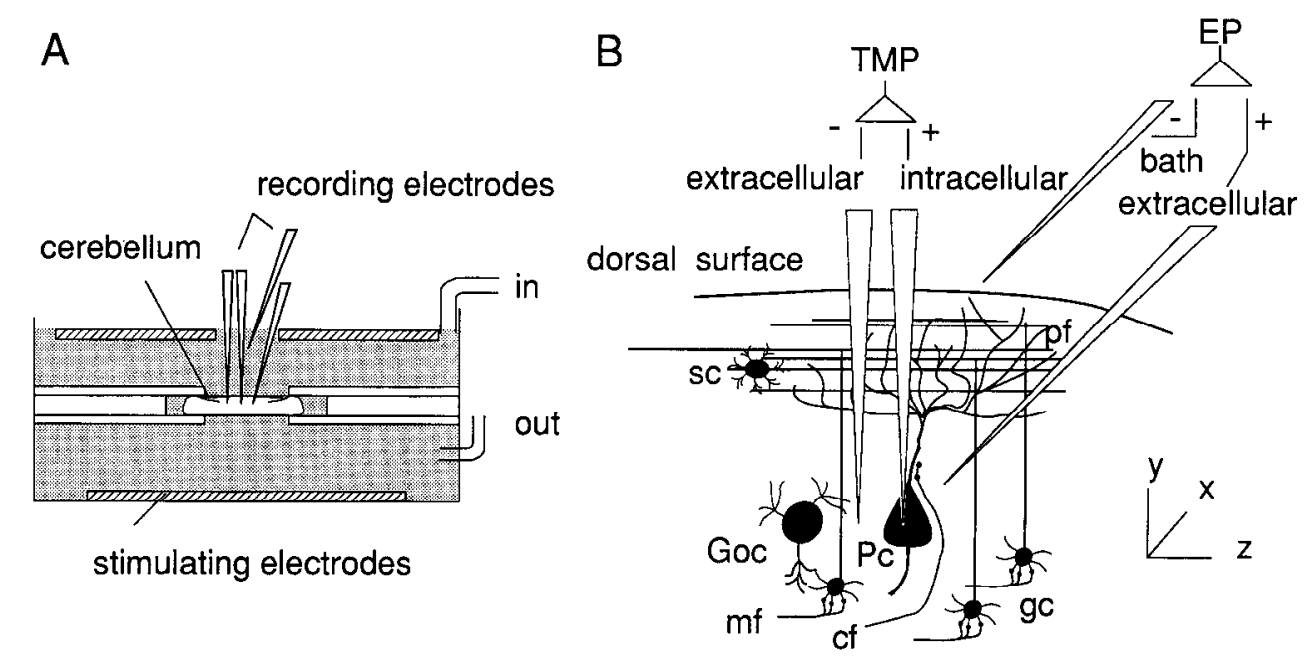

The detector consisted of an asymmetric second-order gradiometer coupled to a DC Superconducting Quantum Interference Device (SQUID; BTI Inc., San Diego, CA). The pickup coil had a diameter of $10 \mathrm{~mm}$; the two upper coils had a diameter of $20 \mathrm{~mm}$ and were placed at 40 $\mathrm{mm}$ distance. The output of the detector was amplified and filtered with DC, $1-\mathrm{kHz}$ bandwidth. The signals were averaged over $100-200$ epochs. The stimulus artifact was cancelled by placing a buck-out coil several centimeters away from the detecting coil and connecting it in series with the stimulator. The buck-out coil, when properly oriented in space, would be sufficient to cancel the artifact. This procedure was very important in the case of the applied sinusoidal field, where the stimulus artifact lasted through the duration of the expected response.

The experimental chamber was placed in a cylindrical magnetic shielding made of hypermalloy (Okada and Nicholson, 1988; Okada et al., 1988a).

Recording of the extracellular electric potentials and CSD. The extracellular recordings were made with a glass micropipette (3-5- $\mu \mathrm{m}$ tip diameter), filled with $\mathrm{NaCl}$ or $\mathrm{Na}$-acetate $(0.5-1 \mathrm{M})$, referred to the potential at the ground electrode $(\mathrm{Ag} / \mathrm{AgCl}$ plate) in a corner of the acrylic chamber. The electrode position could be adjusted with a micromanipulator, which in the case of simultaneous magnetic recordings, had been modified using nonmagnetic brass components. The signal was amplified $(200 \times)$ and filtered (DC, $1 \mathrm{kHz})$.

In order to cancel the sinusoidal artifact, two microelectrodes were used: the first one (signal channel) was in the tissue at a chosen depth, which could be varied during the experiment, for example, when recording a laminar profile; the other (artifact channel) was always placed in the bath, next to the cerebellar surface, in the center of the current pathway. The two outputs were then fed to a differential amplifier, with an adjustable gain for the artifact channel so that the cancellation could be balanced to get the least sinusoidal artifact.

When needed, a fast Fourier transform was applied off line, to filter the fundamental and harmonics of the stimulus artifact, for both extracellular and magnetic field recordings.

The CSDs were calculated from the second spatial derivative of a polynomial function that was fit locally to the laminar profile of the EP. An extracellular conductivity of $0.2 \mathrm{~S} / \mathrm{m}$ was assumed in these calculations.

Recording of the intracellular potentials. The intracellular potentials were recorded through a conventional glass micropipette electrode with submicron tip filled with $\mathrm{K}\left(\mathrm{CH}_{3} \mathrm{COO}\right)(3 \mathrm{M}$; resistance, $60-90 \mathrm{M} \Omega)$ and connected to a bridge amplifier provided with a current-injection circuit (Axo-Clamp 2A). The penetration and sealing of the Purkinje cell membrane were achieved by conventional intracellular recording technique.

Stable resting potentials were typically more negative than $-50 \mathrm{mV}$. The signal was monitored on a digital oscilloscope (Nicolet 206) and recorded on magnetic tape together with the extracellular potential with a $\mathrm{DC}, 3-\mathrm{kHz}$ bandwidth.
For the transmembrane recordings, a second microelectrode was used at the same depth but $100 \mu \mathrm{m}$ from the intracellular one. Transmembrane potential was monitored as the difference of extracellular and intracellular potentials. The relative depths of the two electrode tips were finely adjusted before penetration of neurons so that the transmembrane potential read 0 when a test sinusoidal field was applied (Chan et al., 1988).

\section{Results}

We use the same labels in the figures wherever a specific waveform component is consistently shown, so that the reader can compare particular components across the different paradigms. The identification of the components was primarily based on the effects of pharmacological agents.

\section{Pulsed field}

Basic features

A brief applied electric field lasting 50-300 $\mu$ sec elicited an EP that was very similar to the MEF and intracellularly recorded potential changes (TMP). As shown in Figure 3, the EP response to a short pulse presented a fast component (Fig. 3, component a) with a latency of $1.0-1.5 \mathrm{msec}$, a duration of about $1.5 \mathrm{msec}$, and an amplitude of $1-3 \mathrm{mV}$, and a second component (Fig. 3, component b) with a latency of $3.5 \mathrm{msec}$ and an amplitude of as much as $2-4 \mathrm{mV}$, depending on depth of the recording electrode. The threshold for the second component ranged from 5 to 10 times the field strength necessary to elicit the first component. These responses were specific to the stimulus polarity: when the field was directed from dorsal to ventral surface, the threshold for both components was lower than for the opposite direction, while the threshold ratio between components a and $\mathrm{b}$ was always constant $(1 / 5$ to $1 / 10)$. We recorded a third component, component $\mathrm{c}$ (more visible in the $\mathrm{v}$-d stimulation in Fig. 3). The threshold for component $c$ was generally just above the one for component $b$.

The latency and wave form of MEF (Fig. 3, row 2) matched closely with those of the simultaneously recordcd EP (row 1). The first two components, $a$ and $b$, of the EP were evident in the MEF, with their amplitudes being smaller in response to the $\mathrm{v}-\mathrm{d}$-applied electric field. The direction of magnetic field of these 


\section{dorso-ventral field}
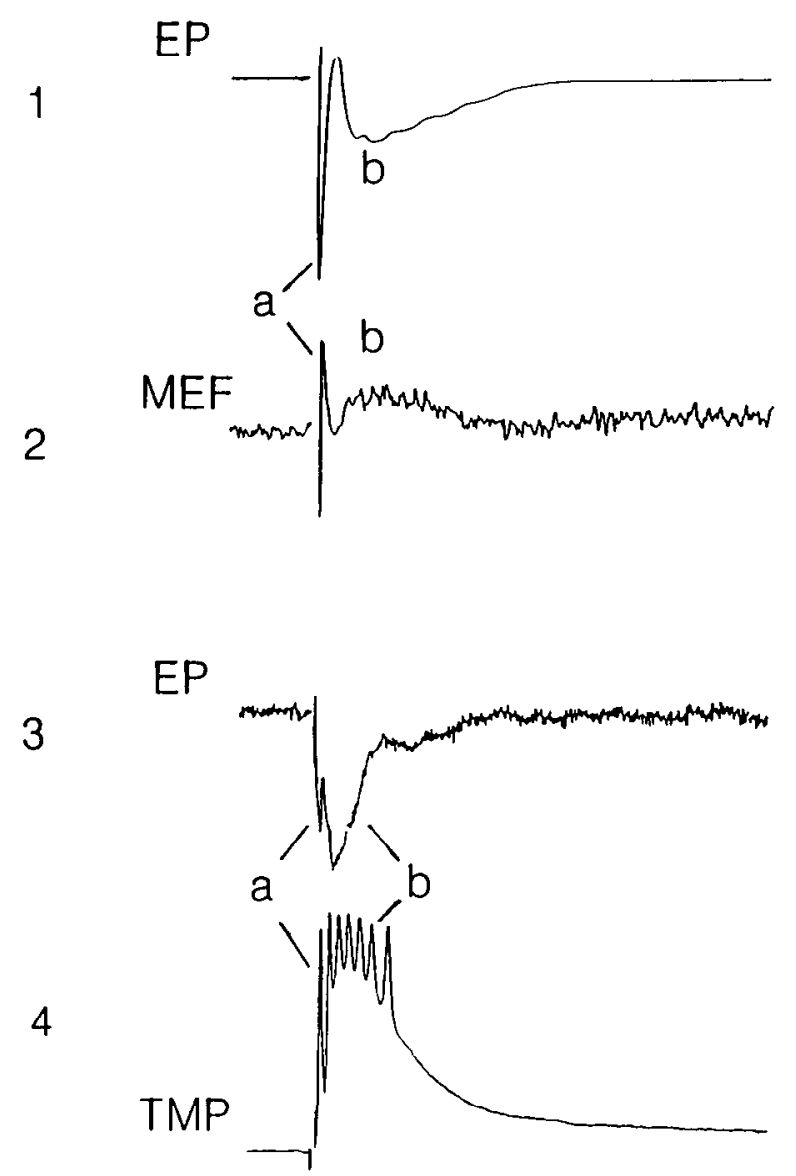

\section{ventro-dorsal field}
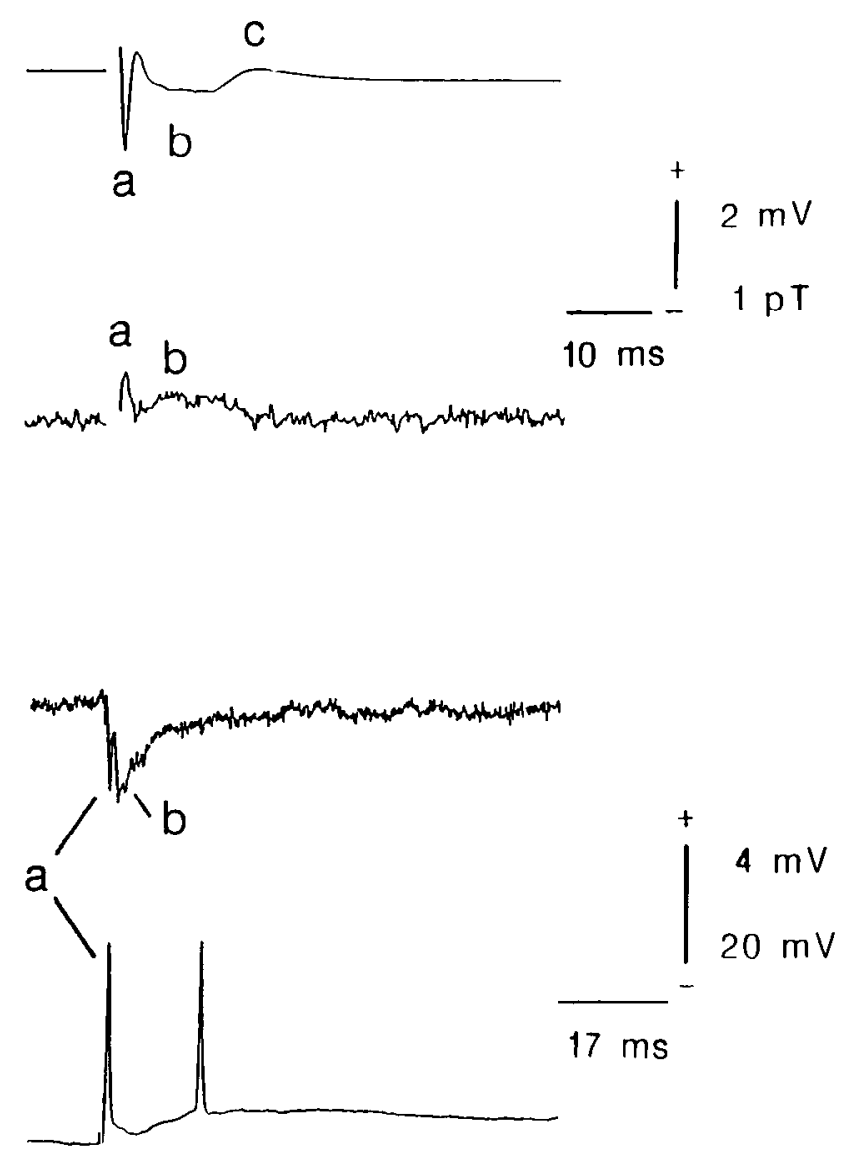

Figure 3. Responses to pulsed electric field recorded in three modalities: EP, MEF, and TMP. The fast response component (a) and the slower component $(b)$ showed similar latencies (1-1.5 msec and $3.5 \mathrm{msec}$, respectively) in all three modalities and when the field was applied in both directions. Also note the greater efficacy of the d-v field in eliciting both components. The amplitude of component $b$ in the TMP response had a step function (i.e., "all-or-none") relation with applied field intensity. $E P$ was recorded in the Purkinje cell layers; $M E F$ was recorded at 13,0 , and $20 \mathrm{~mm}$ from the center of the cerebellum; TMP in this experiment was recorded at $450 \mu \mathrm{m}$ from the dorsal surface (somatic region).

components implied that its underlying generator of current was directed from the ventral to dorsal side of the cerebellum. The equivalent current dipole was located in the center of the cerebellum, as indicated by the location of the two magnetic field extrema along the rostrocaudal axis $(+13$ and $-13 \mathrm{~mm}$ from the center of the cerebellum). The latencies of these components were very similar to those shown in the EP measurements, suggesting that a considerable cell population was involved in the synchronous generation of these currents, giving rise to both $\mathrm{EP}$ and MEF.

The EP was also similar to the TMP recorded simultaneously with the EP from the Purkinje cell (Fig. 3, rows 3, 4). The EPs in these records were somewhat noisy because they were not averaged and were recorded with a bandwidth of $3 \mathrm{kHz}$. The TMP, recorded near the soma, showed an initial spike with an onset latency of $1.2 \mathrm{msec}$ and a peak latency at $1.6 \mathrm{msec}$, which matched component a of the EP. This component resembled the typical sodium spike both in mammalian and turtle Purkinje cells (Llinás and Sugimori, 1980b; Chan et al., 1988) that was likely to be due to antidromic activation, its latency being $1-$ $1.4 \mathrm{msec}$, which was shorter than the typical latency of $3 \mathrm{msec}$ for monosynaptic response in the turtle cerebellum (Hounsgaard and Midtgaard, 1989). This component is again labeled "a." It is likely that the sum of a number of Purkinje cells directly activated by the field gives rise to component a recorded extracellularly. When recorded in more distal positions of the dendritic tree (Figs. 3-5), component a was either very small or absent supporting its origin in the somatic region.

Both TMP and EP showed the second component (component b) at $3 \mathrm{msec}$, peaking at $4.5-5 \mathrm{msec}$, and presenting a fast rising phase and a slow falling phase that lasted for about $16 \mathrm{msec}$.

\section{Pharmacological effects}

Pharmacologically, component a was shown to be due to an antidromic activation of the neurons, whereas the later components were shown to be postsynaptic. Thus, component a was sensitive to tetrodotoxin (TTX). The application of kynurenic acid (KYNA; $7 \mathrm{~mm}$ ) selectively abolished all components, except component a, of EP and MEF that were measured simultaneously (Fig. 4, rows 1, 2). KYNA is known to block synaptic transmission mediated by excitatory amino acids (EAA; Cochran, 1983), including those in the turtle cerebellum (Chesler and 
Normal Ringer

1

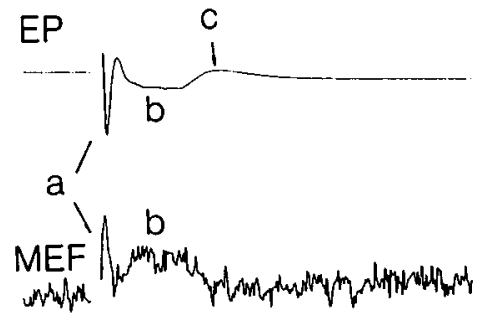

EP

3

4

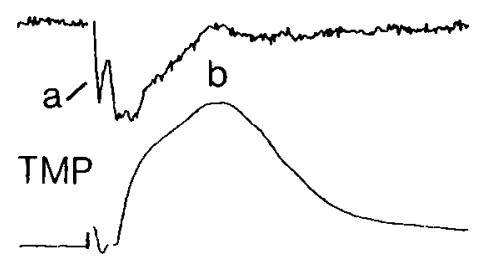

Kyn.A
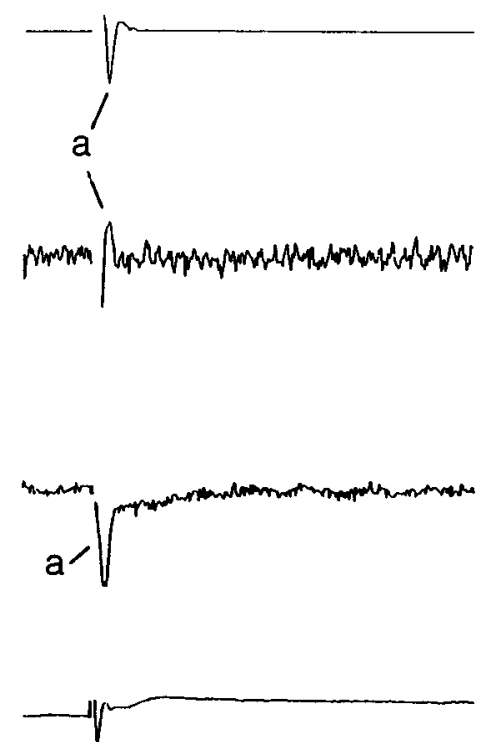

TTX
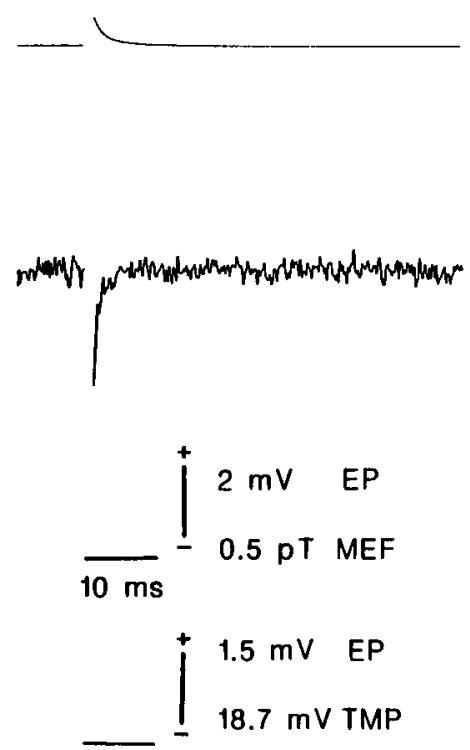

$6.25 \mathrm{~ms}$

Figure 4. Effects of KYNA and TTX on responses to pulsed electric fields. Traces in rows 1 and 2 and in rows 3 and 4 were recorded simultaneously, showing components $a, b$, and $c$. Component $a$ appcared small in the TMP record due to the middendritic location of the microelectrode impalement ( $240 \mu \mathrm{m}$ from the dorsal surface). Addition of $7 \mathrm{mM}$ KYNA (middle column) completely abolished components $b$ and $c$. Further addition of $1 \mu \mathrm{M}$ TTX (right column) abolished component $a$. EP was recorded in the Purkinje cell layer, and MEF was recorded at 13, 0 , and $20 \mathrm{~mm}$.

Chan, 1988; Larson-Prior et al., 1990). TTX (1 $\mu \mathrm{M})$ added into the bath containing KYNA abolished the remaining component (i.e., component a) of both EP and $\operatorname{MEF}(n=21)$.

The concentration of KYNA ( $7 \mathrm{~mm})$, effective in eliminating all components except component a in Figure 4, row 3, was effective in virtually abolishing the corresponding components of the TMP that was measured simultaneously with the EP (rows $3,4)$.

\section{Depth profiles of TMP}

Transmembrane recording of Purkinje cells at various depths showed two kinds of response that could be evoked by a brief pulse of applied electric field in the time window of component b: a graded response rising at $6.5-7 \mathrm{msec}$ latency, suggesting a disynaptic event, that was completely overcome by an all-ornone monosynaptic $(3.5 \mathrm{msec})$ response once a threshold was reached (Fig. 5, recording at $400 \mu \mathrm{m}$ ). These slow components most likely correspond to the population response labeled " $b$ " in the extracellular recordings (EP and MEF). Figure 5 shows that this relatively slow response was present in all our recordings taken at different depths in the molecular layer, even though its features were modified in the superficial molecular layer, in that the peak was delayed, while the total duration remained the same (around $16 \mathrm{msec}$ ) as described previously (Chan et al., 1989).

\section{Laminar EP profile and CSD profile}

The EP due to a pulsed field was similar to the EP produced by a peduncular stimulation in terms of their laminar potential profile (Fig. $6 A$ ) and CSD profile (Fig. $6 B$ ) across the depth of cerebellum. A stimulus artifact segment was removed in these records $(0.8 \mathrm{msec}$ for the laminar potentials, $0.6 \mathrm{msec}$ for the CSDs). The responses to the applied field showed component a peaking at $1.2 \mathrm{msec}$ latency, which could be seen more clearly in the CSD profile (Fig. $6 B$ ). These profiles revealed two components, components $b_{v}$ and $b_{1}$, that were not clearly seen in the records of Figures 3 and 4 . Component $b_{0}$ reversed its polarity about $30-50 \mu \mathrm{m}$ more dorsal to component a, and component $b_{1}$ reversed its polarity $50 \mu \mathrm{m}$ more dorsal to component $\mathrm{b}_{0}$. Component $\mathrm{c}$ was not clearly present in these records, but results from other cerebella (e.g., Fig. 9, leftmost column) showed that its polarity reversal occurred at about the same depth as component $\mathbf{b}_{0}$.

The responses produced by these two types of stimulation differed, however, in the latency of the major components. In response to the applied pulse field, the latencies of components $a$ and $b_{0}$ were 1.2 and $4.4 \mathrm{msec}$, respectively, with a latency difference of $3.2 \mathrm{msec}$ between these two components. The latencies of the respective components in response to the peduncular stimulation, on the other hand, were 2.4 and $5.4 \mathrm{msec}$, with a latency difference of $3.0 \mathrm{msec}$. These latencies are consistent with the notion that the applied field directly activated component a without synaptic or conduction delay, whereas the peduncular stimulation activated component a with a conduction delay. The similar interval between the two components in the two cases suggested a monosynaptic transmission delay in both cases.

Just as for EP, the wave form of the MEF produced by the bricf applied electric field resembled the one obtained for peduncle stimulation (Okada et al., 1989). 


\section{Sinusoidal field}

\section{Basic features and pharmacological effects}

The EP in response to the spatially uniform, sinusoidally amplitude-modulated applied field $(4-6 \mathrm{~Hz})$ presented a complex of responses with clear-cut relationship to the phase (Fig. 7). In all of the records shown in this and later figures, the stimulus was applied at the beginning of the record and lasted for 2-3 cycles, after which the stimulus ceased. Thus, the responses to the first cycle of the stimulus are similar but not exactly the same as those produced by the later cycles.

In normal Ringer's solution, the d-v field elicited a response complex consisting of a component, labeled "a," which had more than one spike, typically three to five, with a frequency that was around $160 \mathrm{~Hz}$, followed by two components, labeled "b" and "c." The v-d field elicited a diphasic response that in the granular and Purkinje cell layers was typically positivenegative. We label this response "d." At a low applied field amplitude, only component a was evident, but presumably without a sufficient population synchrony to produce spikelets in the responses (Fig. 7, top record). As the field amplitude was raised, spikes emerged in component $a$, then components $b$ and $c$ emerged, followed by component $d$.

Most of components $b$ and $c$ and some portion of component $\mathrm{d}$ were eliminated by the EAA antagonist KYNA ( $7 \mathrm{~mm}$; Fig. 7). Because components $b$ and $c$ elicited by the $d-v$ field were sensitive to KYNA, they may be the correlates of the postsynaptic responses $b$ and $c$ to the pulsed field (see Fig. 3). The bath application of KYNA brought out component a more clearly. This result also demonstrated that component $d$ was in part due to a potential, positive in the granular layer, that was insensitive to the blocker of EAA synaptic transmission.

The addition of $\mathrm{Mn}^{2+}(10 \mathrm{mM})$ to the bath containing KYNA largely removed the KYNA-insensitive portion of component d (Fig. 7). $\mathrm{Mn}^{2+}$ did not eliminate component a, however, though it apparently raised the threshold for activation of this component, as evidenced by the absence of spike wave forms at a stimulus strength of two times threshold, that were present in the Ringer's solution without $\mathrm{Mn}^{2+}$ and also by a noticeable delay in onset latency of this component. This spike wave form was eliminated by TTX $(1 \mu \mathrm{M})$. However, some distortion remained in the response wave form after bath application of TTX, probably due to surviving $\mathrm{K}$ conductances.

The latency of all the components in Figure 7 decreased with an increase in amplitude of the applied electric field. This decrease may indicate that these components were activated when the applied field reached some threshold amplitude that was specific to each component.

\section{Laminar profile of field potential and CSD}

The laminar profiles of the EP and CSD reveal the locations of the current sink and current source of the population responses activated by the applied electric field. It should be noted in examining these records that the recording glass micropipette was inserted into the cerebellum with an oblique angle of about $30^{\circ}$ with respect to the cerebellar surface. Thus, the estimated depth indicated here may not be strictly accurate. For this reason, the laminar potential profile and CSD profile were obtained along the same track, and they were compared with the CSD for the response to the pulse field obtained at same depths.

The laminar potential profile in normal Ringer's solution (Fig. 8) showed that the first spike in component a was negative in
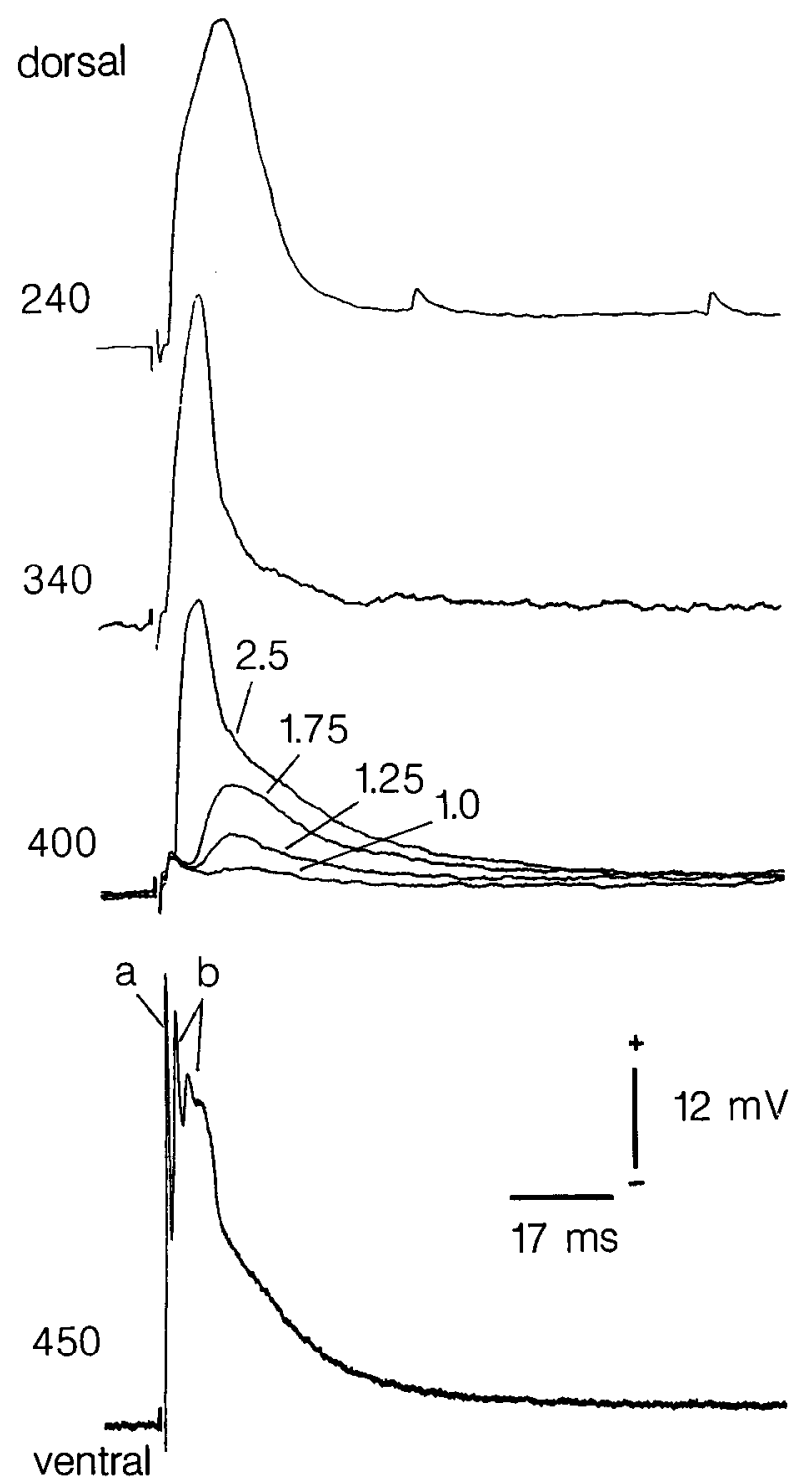

Figure 5. Depth profile of pulsed electric field-evoked TMP responses in the Purkinje cell dendrite. The records shown were obtained from four separate Purkinje cells impaled at different depths. The numbers preceding each trace indicate real depth in microns from the dorsal surface (the top three traces were recorded in the molecular layer; the bottom trace, in the Purkinje cell layer). The brief break in the trace preceding each response marks the stimulus artifact. Note that component $a$ was most prominent in the deepest location. Component $b$ had a greater latency at distal locations. The responses of $400 \mu \mathrm{m} \mathrm{dem}-$ onstrate an all-or-none short-latency $b$ component and a set of graded, presumed disynaptic responses (with latency of $7 \mathrm{msec}$ ), which may correspond to the component $b_{0}$.

the ventral, granular region of the cerebellum. The direction of this spike reversed at a nominal depth between 700 and 800 $\mu \mathrm{m}$ from the ventral surface. The intracellular current for this component was thus directed from the ventral to the dorsal side of the cerebellum, in agreement with the direction of the underlying current for component a inferred from the MEF data. The second component was negative in the granular layer with its maximum amplitude at a nominal depth of about $700 \mu \mathrm{m}$ and positive in the molecular layer. Component c, positive in the granular layer, was clearly present in these records. This component seemed to be a mixture of several types of currents 
A

Laminar profile

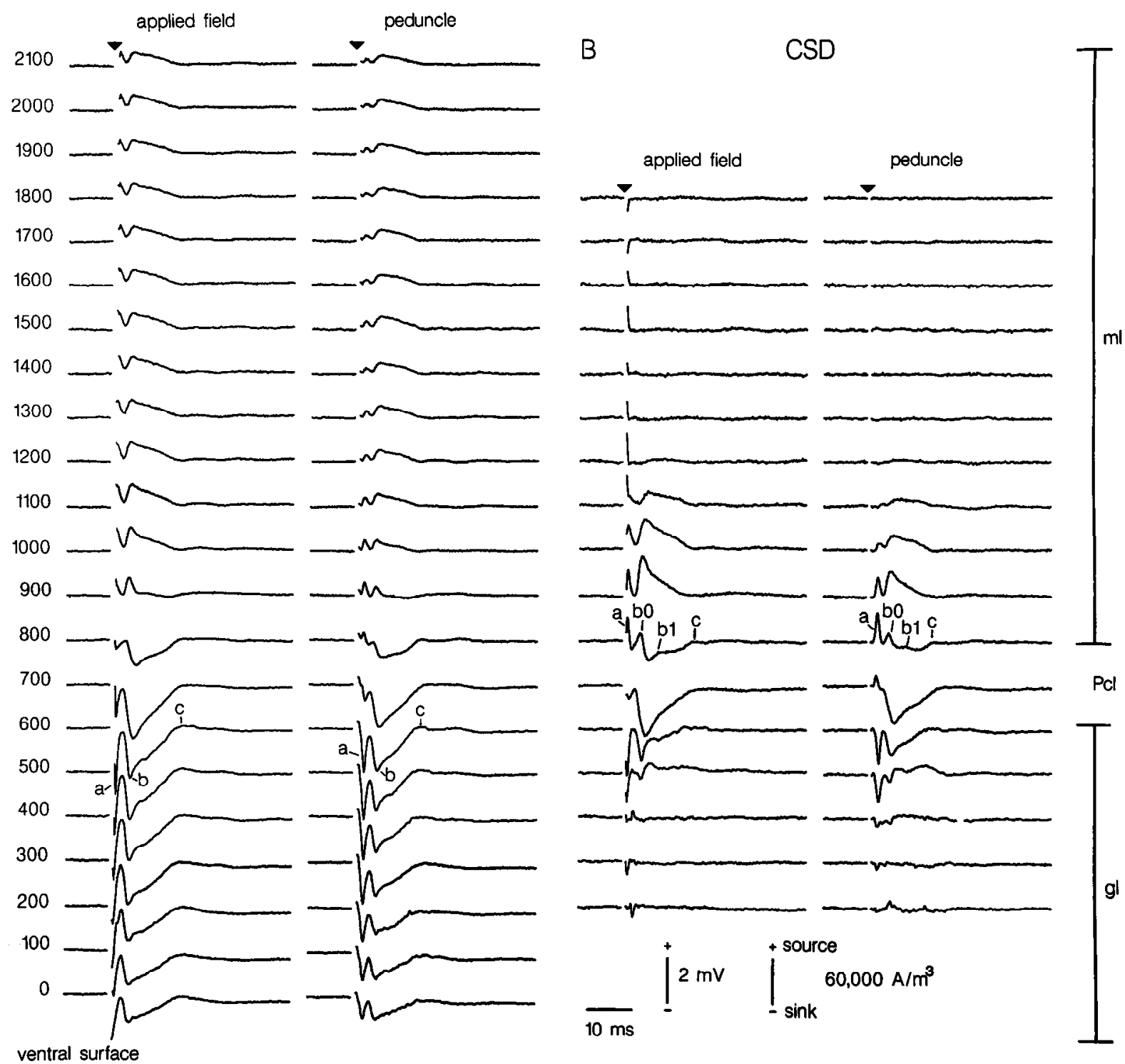

Figure 6. Laminar EP and CSD profile of responses to pulsed electric field and peduncular stimulation. $A$, laminar EP profile. The responses on the left column were evoked by pulsed electric fields; those on the right were evoked by peduncular stimulation using bipolar electrodes. The numbers on the left (which apply to both $A$ and $B$ ) denote nominal depths of recording in microns from the ventral surface uncorrected for an approximately $30^{\circ}$ angle of approach of the microelectrodes (see Fig. 1). Note that the latencies of component $a$ evoked by the two methods were different, yet the intervals between $a$ and $b$ were unchanged. $B$, The current source and sink locations for components $a$ and $b$ showed a correlated pattern of reversal to $A$. Component $b$, however, showed two subcomponents, $b_{o}$ and $b$, having a more dorsal source location than $\mathrm{b}_{0}$. A conductivity of $0.2 \mathrm{~S} / \mathrm{m}$ was assumed in these computations. The vertical marker roughly indicates the cell layers: $m l$, molecular layer; $P c l$, Purkinje cell layer; $g l$, granular layer.

because its wave form changed with depth. Its polarity reversed at around $1100 \mu \mathrm{m}$. The response to the $\mathrm{v}$-d field was biphasic, being positive-negative in the granular layer. Its polarity did not show clear reversal with depth, and its maximum amplitude was at $600-800 \mu \mathrm{m}$.

The laminar profile of the EP in KYNA-added saline showed very little response except for the TTX-sensitive component that reversed polarity at about $700 \mu \mathrm{m}$, comparable to the reversal point for the same component in normal Ringer's solution. The KYNA-insensitive component produced in response to the v-d field, evident in Figure 7, was not present in these records, probably because of insufficient strength of the applied field.

The CSD analysis reveals the distribution of current sink and source locations for all the components (Fig. 9). The current sink for component a was located in the region between 400 and $600 \mu \mathrm{m}$ from the ventral surface. Its source was located in the region above $800 \mu \mathrm{m}$ with the polarity reversal occurring at a depth of $700 \mu \mathrm{m}$. Component b showed its current sink at a depth of $600-700 \mu \mathrm{m}$, with the polarity reversal occurring between 800 and $1100 \mu \mathrm{m}$, and its current source, in the region between 1200 and $1600 \mu \mathrm{m}$. The slowly varying portion of 


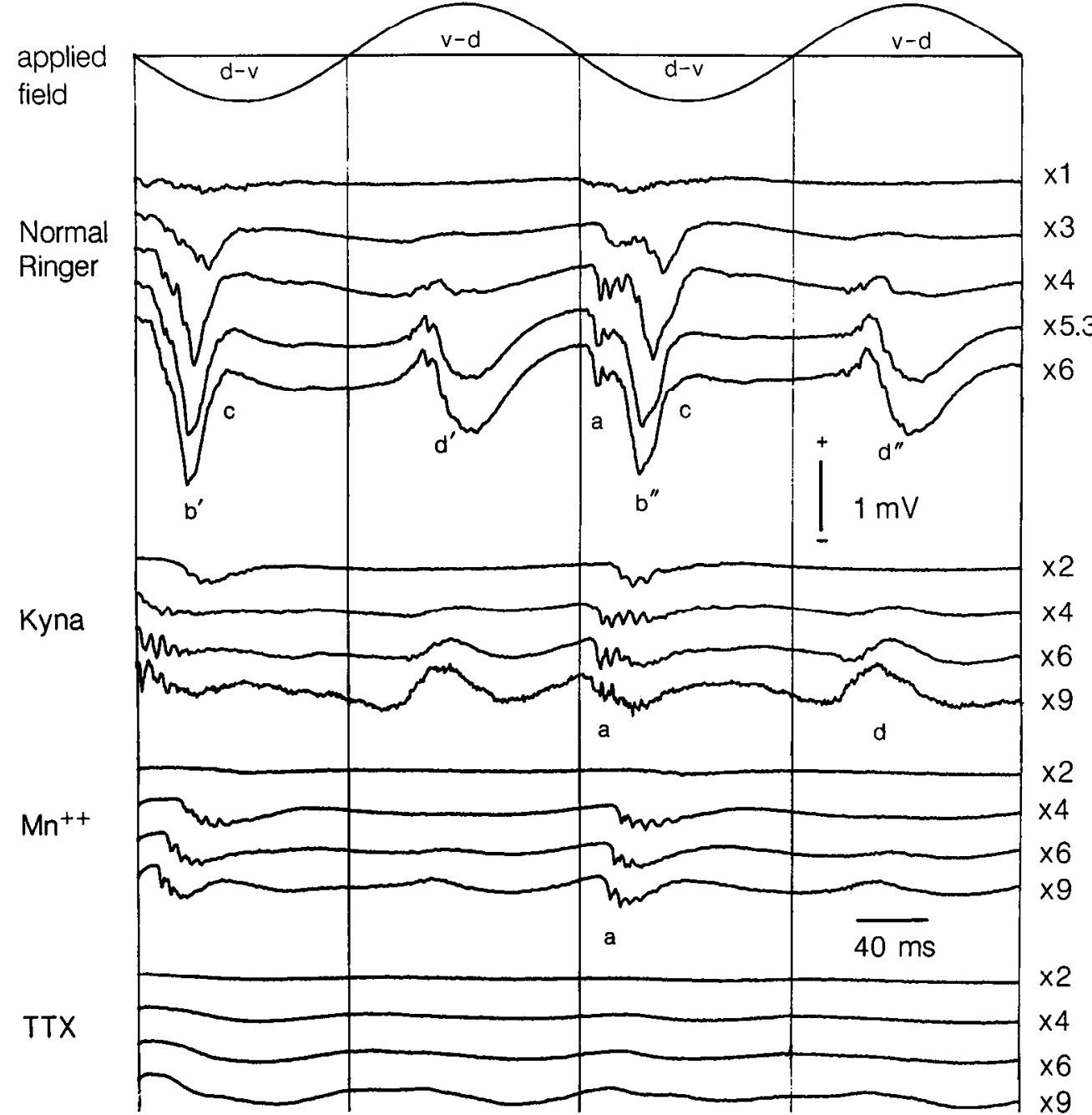

Figure 7. EP responses to applied sinusoidal electric fields: strength-response relation and pharmacologic properties. The sinusoid field shown on the top provides phase references for all response components shown. $d-v, \mathrm{~d}-\mathrm{v}-$ directed field; $v$ - $d, \mathrm{v}$-d-directed field. The traces in each of the four sets of records here illustrate progressive changes in each component when field intensity was increased by multiples of threshold field strength (indicated by numbers at the right). Components $a-$ $c$ were comparable to the response components evoked by pulsed electric fields, but component $d$ was exclusively evoked by sinusoidal field in the v-d direction. The labels $b^{\prime} b^{\prime \prime}$ as well as $d^{\prime}$ and $d^{\prime \prime}$ indicate the different wave form of the same components during two different cycles of sinusoidal field. Note the earlier appearance of various components at higher field amplitudes. The effects of sequential addition of $7 \mu_{M}$ KYNA, $10 \mathrm{mM} \mathrm{Mn}^{2+}$, and $1 \mu \mathrm{M}$ TTX to the same cerebellum are shown in the lower three sets of records. Note the increase in threshold of component $a$ in the $\mathrm{Mn}^{2+}$ added Ringer's solution. component $\mathrm{c}$ had its maximum current source around 600-700 $\mu \mathrm{m}$, its polarity reversal between 900 and $1100 \mu \mathrm{m}$, and its current sink between 1200 and $1600 \mu \mathrm{m}$. The spike wave forms in component $\mathrm{c}$ showed two reversals, one at a depth of 700 $\mu \mathrm{m}$ and another at $1100 \mu \mathrm{m}$. In both cases, the current sink was above (more dorsal to) the current source. The current sinksource pair for component d that was abolished by KYNA was located in the granular layer (depth, 400-600 $\mu \mathrm{m}$ ).

The distribution of current sink-source pair and reversal positions for the sinusoidal response were similar to those for the pulse response shown on the left column of Figure 9, which were obtained at the same depths as those for the laminar potential profile in normal Ringer's solution. The underlying cellular origin of these current sink-source pairs will be considered in the Discussion.

\section{Intracellular potential versus extracellular field potential}

The TMP (Fig. 10) showed a strong modulation by the sinusoidal field. In response to the d-v field, $\mathrm{Na}^{+}$-plateau with $\mathrm{Na}^{+}$ spikes could be elicited as previously reported (Chan et al., 1988). With a further increase in stimulus strength, a conductance change occurred, resembling a $\mathrm{Ca}^{2+}$ plateau with $\mathrm{Ca}^{2+}$ spikelets. This response was abolished by KYNA; thus, we con- cluded that it corresponded to component $b$ due to the postsynaptic response to climbing fiber activation. We found that the $v$-d field did not elicit any active response in the somatic recordings, while in more distal locations, a response could be elicited with a relatively high threshold. In Figure 10, two examples are shown in which this contrast is evident. The response to this $\mathrm{v}-\mathrm{d}$ field in the dendritic location is also abolished by KYNA, thus indicating that a synaptically mediated event is involved. Increasing the amplitude of stimulation, we could still record activity presumably due to dendritic voltage-dependent $\mathrm{Ca}^{2+}$ conductance (Llinás and Nicholson, 1971; Llinás and Sugimori, 1980a; Chan et al., 1989), which was KYNA resistant.

\section{$M E F$ versus $E P$}

The MEFs due to the sinusoidal stimulus are shown in Figure 11 together with the EPs. In normal Ringer's solution, the EP showed all four components, $a-d$, though component $b$ was not well distinguished from component a. The directions of the MEF components were consistent with the MEF evoked by the pulsed field. The first component of MEF, which most probably corresponded to a mixture of components $a$ and $b$ of the EP, was directed in such a way that its underlying current was ventral 


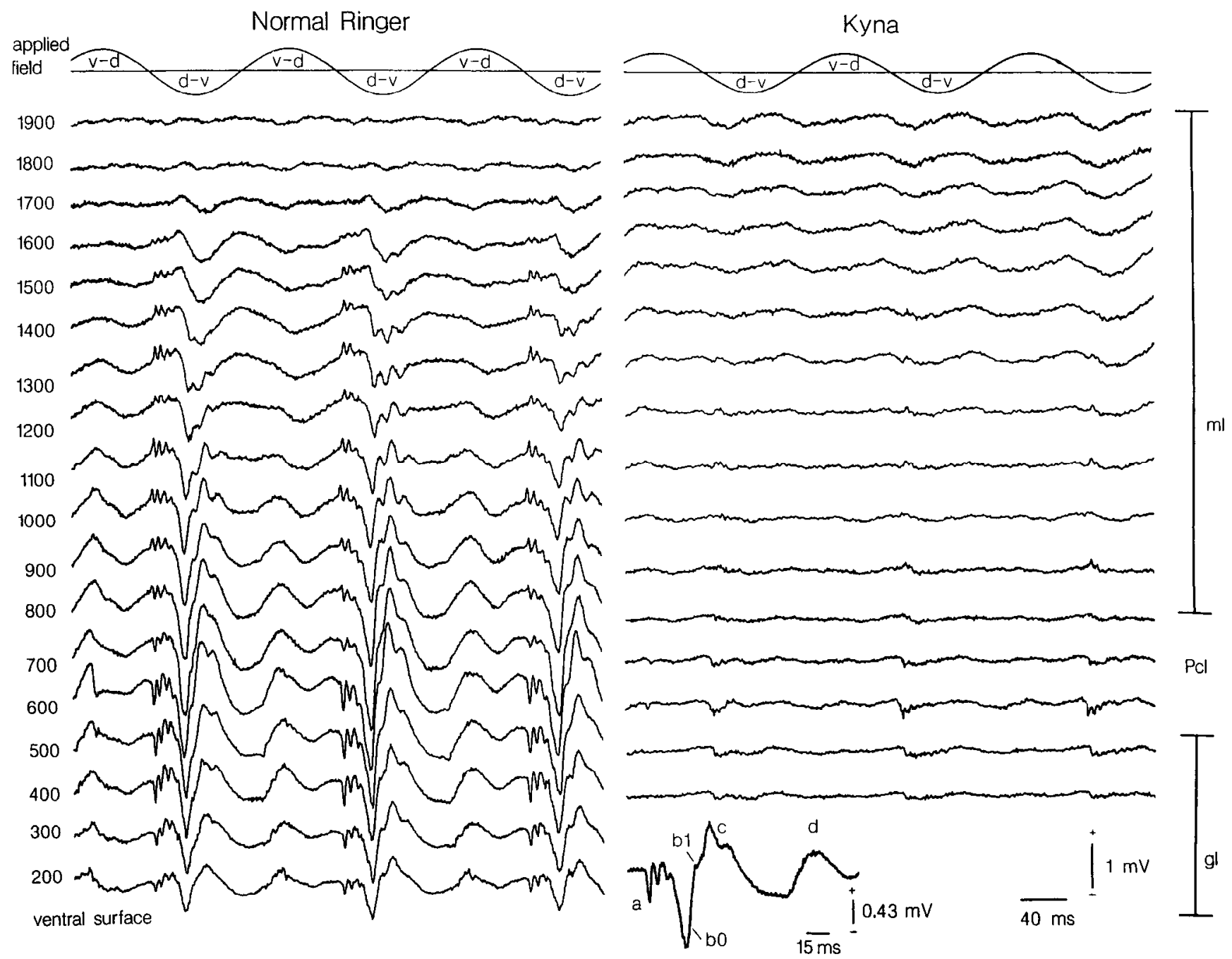

Figure 8. Laminar profiles of EP responses to sinusoidal applied fields. Left, Normal Ringer's solution. Detailed configuration of response components is shown in the expanded trace in the inset at bottom right. Right, Ringer's solution with 7 mM KYNA. Only component $a$ persisted at the field strength used in this experiment. $m l$, molecular layer; $P c l$, Purkinje cell layer; $g l$, granular layer. Sinusoidal field at $t o p$ is as described in Figure 7.

to dorsal, just as for the corresponding components of the pulseevoked MEF. The second component of MEF, corresponding in latency with component $c$ of the EP, was directed in such a way that its underlying dipolar current was dorsal to ventral. The MEF corresponding to component $d$ was always small, even if it was present, suggesting a poor synchrony of the underlying current.

The antagonist of EAAs, KYNA ( $7 \mathrm{~mm})$, reduced components b-d of the EP. TTX $(1 \mu \mathrm{M})$ eliminated the deflection corresponding to component a of the EP. However there were some residual responses.

The administration of iodoacetate (IAA; $10 \mathrm{~mm}$ ), which is a glycolytic metabolism blocker, eliminated this residual component of both EP and MEF (Fig. $11 B$ ). In examining Figure $11 B$, it should be noted that the EP was measured in the molecular layer, so that components $a$ and $b$ of the EP are positive, that is, opposite in polarity from those shown in the previous records, which were taken in the granular layer. In comparison to Figure $11 \mathrm{~A}$, the response to the $\mathrm{v}$-d field was stronger in both the EP and the MEF, so that the component surviving KYNA was activated by the v-d field in this experiment. This component was blocked by IAA.

\section{Discussion}

The present study was designed to characterize better the population responses elicited by applied fields in this preparation. The EP and MEF were used as measures of the population response. The laminar profile of the CSD derived from the laminar profile of the EP reveals the distribution of current sinks and sources associated with the components of the EP (Nicholson and Freeman, 1975; Mitzdorf, 1985). The MEF relates directly to intraneuronal currents within the tissuc, and the direction of the MEF indicates the direction of the underlying current (Okada, 1989). Together with pharmacological manipulations and the intracellular recordings, the EP and the MEF can thus reveal the nature of currents activated by a particular stimulus.

Both the temporal wave form and latency of the EP and MEF elicited by a pulsed field were nearly identical; thus, these two response modalities together revealed the nature of the popu- 
A Normal Ringer B

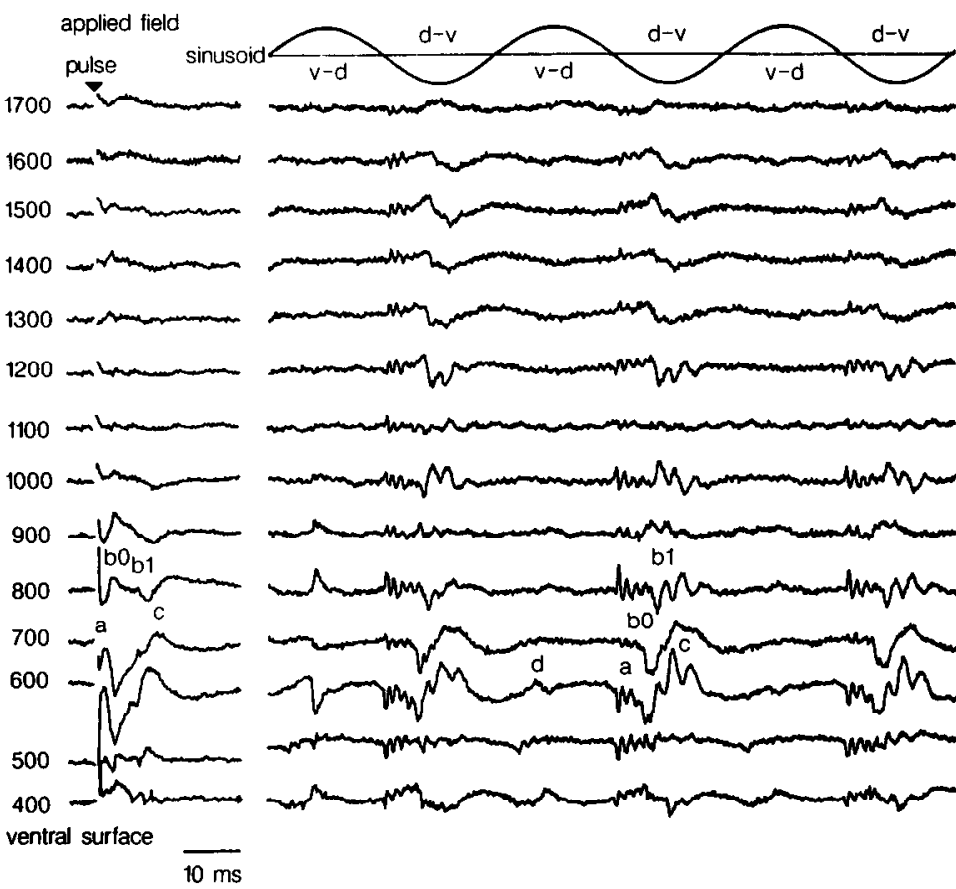

C

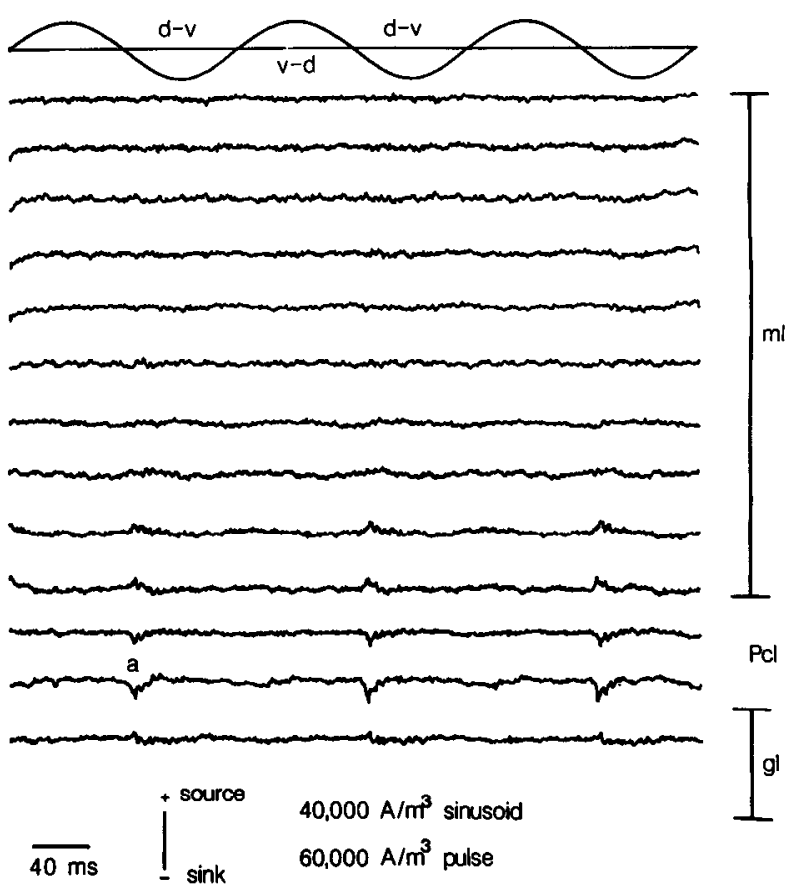

Figure 9. CSD analysis of pulsed $(A)$ and sinusoidal $(B$ and $C)$ field-evoked responses, showing location of sources and sinks of the various response components. $C$ shows no change of sink/source location of component $a$ in KYNA. The depths from the ventral surface indicated by numbers on the left apply to traces in the same rows of $A-C$. Time scale in $A$ is four times more expanded than that of $B$ and $C$. The $n u m b e r s$ on the left (which apply to all recordings) denote nominal depths of recording in microns from the ventral surface uncorrected for an approximately $30^{\circ}$ angle of approach of the microelectrodes (see Fig. 1); the morc ventral recordings do not appear in this figure. $m l$, molecular layer; $P c l$, Purkinje cell layer; $g l$, granular layer. Sinusoidal field at top is as described in Figure 7.

lation response to the brief pulse of electric field. Both EP and MEF consisted of a fast spike with a latency of about $1.2 \mathrm{msec}$. This component was found to survive KYNA, an EAA antagonist, but was abolished by TTX, which blocks voltage-dependent $\mathrm{Na}^{+}$channels. The TMP corresponding to this component was maximum near the Purkinje cell soma, indicating that the TTX-sensitive component was produced by direct stimulation of the Purkinje axons or soma, which is known to contain voltage-dependent $\mathrm{Na}^{+}$conductance channels (Llinás and Sugimori, $1980 \mathrm{~b})$. The short latency $(1.2 \mathrm{msec})$ to the peak of this component indicates that there was no conduction delay or synaptic transmission delay, unlike the corresponding component evoked by the peduncle stimulation. An alternative hypothesis, which does not necessarily rule out the contribution of the Purkinje cell axonal spike, is that this component was in part due to the orthodromic activation of the ascending portion of climbing fibers, because there was a strong postsynaptic component in the EP and MEF elicited by the pulsed field. Their relative contributions cannot be determined on the basis of the present study. The effectiveness of the applied field directed from the dorsal to the ventral surface of the cerebellum, relative to the field of opposite direction, suggests that this initial spike, as well as the later components of the pulse response, was due to the depolarization of the ventral portion of the Purkinje cell and the ascending portion of climbing fibers.

The postsynaptic responses in EP and MEF consisted of several components. The component labeled " $b$ " was found to be separable into two subcomponents, $b_{0}$ and $b_{1}$, based on the laminar profiles of the EP and CSD. The various lines of evidence point to a hypothesis that component $b_{0}$ was produced by the depolarization current in Purkinje cell dendrites produced by climbing fibers. First, the polarity reversal of the current underlying $b_{0}$ and $b_{1}$ occurred about 50-100 $\mu \mathrm{m}$ and $100-150$ $\mu \mathrm{m}$, respectively, more dorsal to the location of the polarity reversal for the TTX-sensitive directly activated spike (component a). Assuming that component a was in large part due to the directly activated $\mathrm{Na}^{+}$currents, the relative locations of the current sink-source pair for the climbing fiber-activated postsynaptic current should have its polarity reversal point just above the polarity reversal point for component a as found here, because the climbing fibers terminate in the proximal third of the Purkinje cell dendrites (Künzle, 1985). Second, the postsynaptic component of the TMP also consisted of a disynaptic wave form that may be attributable to the mossy fiber input into the Purkinje cell and another component with a shorter latency that appeared after the stimulus pulse amplitude of the applied field was made stronger than the threshold for the disynaptic response. The latter is attributable to the climbing fiber input (Hounsgaard and Midtgaard, 1988). When the climbing fibers are stimulated, a $\mathrm{Ca}^{2+}$-dependent afterhyperpolarization has been recorded intracellularly (Chan et al., 1989; Hounsgaard and Midtgaard, 1989) that occurs when a sufficient amount of depolarization is provided to the cell. In our experiments, such a condition was present when the amplitude of the pulsed or the sinusoidal field was increased sufficiently (about 10 times the threshold for the TTX-sensitive initial spike). Thus, it appears that component $c$ of the pulse EP shown in Figures 3, 4, and 9 was actually the population response coming from the $\mathrm{Ca}^{2+}$ dependent afterhyperpolarization.

The main effects of the applied field on the EP and MEF were 
Figure 10. TMP responses to applied sinusoidal electric fields: recordings through microelectrodes that impaled the mid-dendritic (left) or primary dendritic/somatic region (right). The top set of traces in each panel was recorded in normal Ringer's solution; the lower set, in Ringer's solution with 7 mM KYNA. The bottom two traces indicate the sinusoidal field directions and phases. EP was recorded, simultaneously with the TMP recording, in the Purkinje cell layer through a second pair of microelectrodes, demonstrating the temporal correlation of the various components in the two modes of recording.

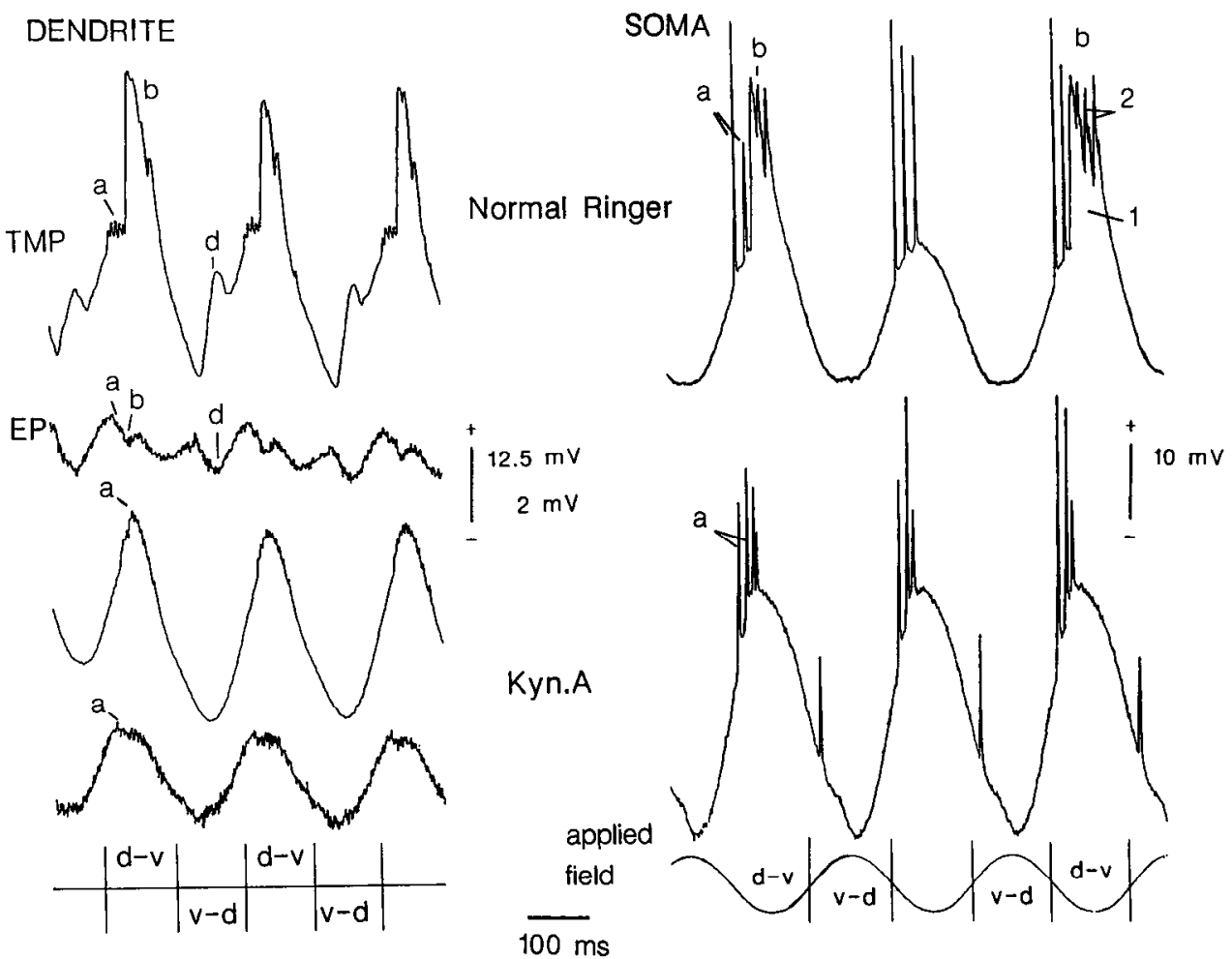

the postsynaptic activations, as demonstrated by the application of an EAA blocker. This is partly due, at least for pulsed applied ficlds, to the more synchronized nature of such responses. In the previous experiments (Chan and Nicholson, 1986; Chan et al., 1988), this contribution was not observed because the stimulation strength and frequency were likely to be subthreshold for this response. As a matter of fact, the stimulation strength used in that study was between 10 and $90 \mathrm{mV} / \mathrm{mm}$, while the fields used presently range between 20 and $500 \mathrm{mV} / \mathrm{mm}$.

The sinusoidal, amplitude-modulated, spatially uniform electric field produced population responses that were markedly different for the two phases (directions) of the applied field (Figs. 8-11). The field directed from the dorsal to the ventral side of the cerebellum elicited responses that were in many ways very similar to the EPs and MEFs observed in response to the pulse. Component a had the lowest threshold of activation just as for the corresponding component of the pulsed response. As for the pulse response, this component survived in the saline solution with KYNA and $\mathrm{Mn}^{2+}$ added, but was TTX sensitive. This behavior was also observed in the TMP. Also the location of the current sink-source pair for this component was similar in the EP elicited by the pulse and sinusoidal stimuli. Thus, it was most likely due to $\mathrm{Na}^{+}$channels located in the axons and soma of Purkinje cells and perhaps in the climbing fibers. The repetitive spiking seen in these responses at a rate of up to $160 \mathrm{~Hz}$ disappeared with any further increase of stimulus strength, due to either inactivation occurring for high frequencies or recruitment of inhibitory pathways. Consistent with the latter hypothesis, the spiking disappeared as soon as the postsynaptic component $\mathrm{b}$ appeared, though it could persist even during this period as seen in the EP after KYNA was added to the saline bath. This disappearance of spiking suggests that spiking was intrinsic to Purkinje cells rather than activated by the climbing fibers, because the latter should not be subject to intracerebellar inhibition. Again consistent with the conclusion that this component was $\mathrm{Na}^{+}$-channel mediated, its threshold increased in $\mathrm{Mn}^{2+}$ added Ringer's solution, probably due to an incrcasc in the cation shielding effect (Nicholson, 1980). Component $b$, which was abolished by KYNA, had its current sink at the same depth as the corresponding component for the pulse, but its current source was more distributed in the molecular layer in comparison to the response to the pulse (Fig. 9). The location of the current sink indicates that it was produced by the depolarization of the proximal end of the Purkinje cell dendrites, just as in the case of the response to the pulse. Consistent with this conclusion, the dipolar component of the current generator of the MEF for this component was oriented from the ventral to the dorsal side of the cerebellum, which could suggest a spreading of the EPSP from proximal to distal dendrites.

Component $\mathrm{c}$ was more complex in the response to the sinusoid compared to the pulse. It consisted of a slowly varying component and a series of spikelets. The slowly varying component had its current sink in the molecular layer, with its corresponding current source in the granular/Purkinje cell layer. This pattern indicates either an excitatory input in the molecular layer or an afterhyperpolarization in the Purkinje cell layer, as hypothesized for the corresponding component of the response to the pulse. The spikelets showed two current sink-source pairs, indicating a current sink in the deep and shallow regions of the molecular layer. The origins of these components are, however, unclear from this single study.

The $v$-d phase of the sinusoidal stimulus presented a different pattern of activation, in terms of reversal of the EP. The positivity in the granular layer without obvious polarity reversal in the molecular layer suggests that it was due to an inhibitory synaptic input located in the granular layer. We have tested this hypothesis by bath application of picrotoxin $(0.1 \mathrm{mM})$, but we observed no effect on this wave form $(n=5)$. The TMP in 
A
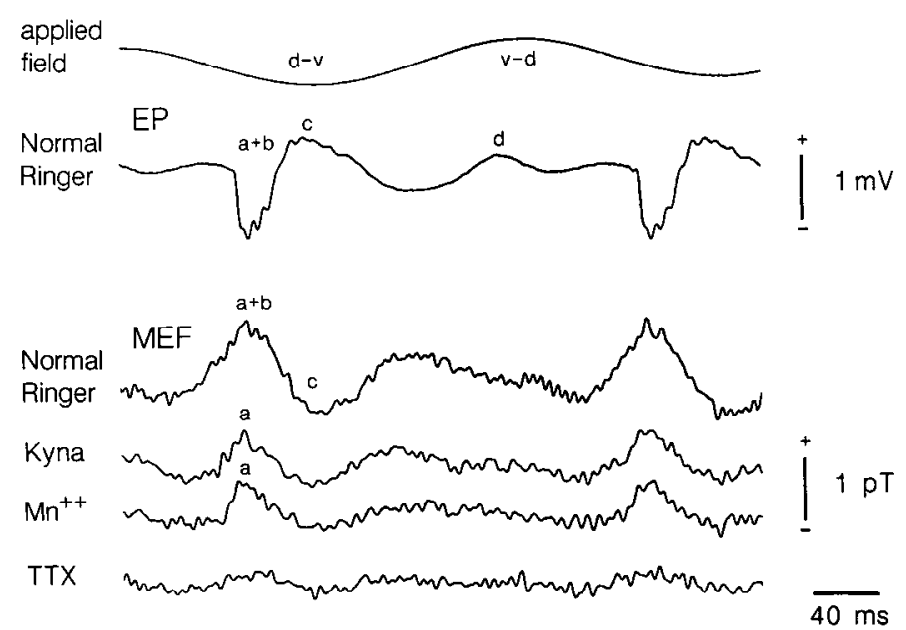

B
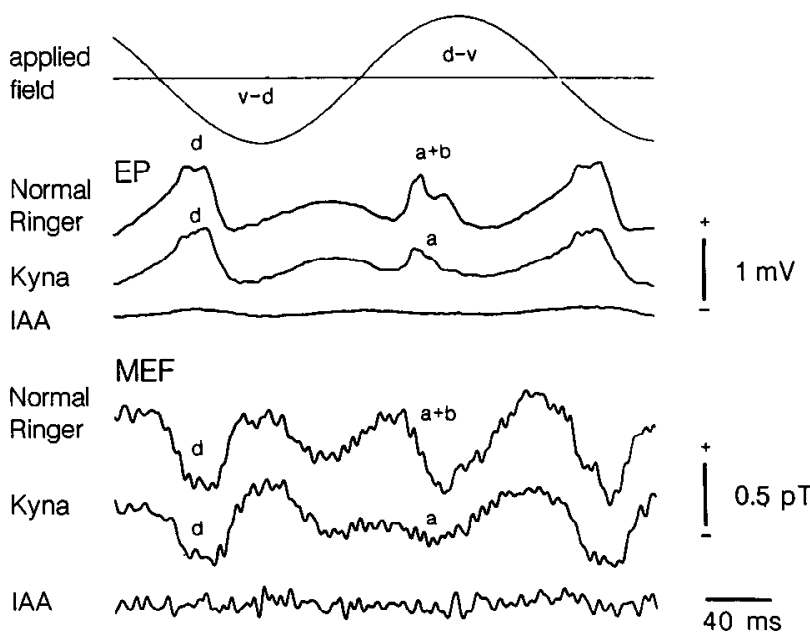

Figure 11. MEF responses to applied sinusoidal electric fields: pharmacologic properties and correlation with EP. $A$ : Top traces, EP responses at the Purkinje cell layer recorded simultaneously with the MEF in normal Ringer's solution showing components with the same phase relation as MEF. Bottom traces, MEF responses recorded at $(x, y, z)=(13,0,20) \mathrm{mm}$ in normal Ringer's solution and in sequentially bath-applied KYNA $(7 \mathrm{mM}), \mathrm{Mn}^{2+}(10 \mathrm{mM})$, and TTX $(1 \mu \mathrm{M}) . B$, Effects on EP (top traces) and MEF (bottom traces) of sequentially bath-applied KYNA (7 mM) and IAA (10 mM). For $B$, EP was recorded from mid-molecular layer (700 $\mu \mathrm{m}$ from the ventral surface); $\mathrm{MEF}$, at $(\mathrm{x}, \mathrm{y}, \mathrm{z})=(-13,0,20) \mathrm{mm}$.

dendritic recordings, but not in the somatic ones, showed a response in this phase that was sensitive to glutamate blocker. Our hypothesis for this KYNA-sensitive response of the TMP and the EP is that it could be due to direct activation of either ascending granular cell axons or mossy fibers, which elicits a postsynaptic response in the Purkinje cells. This direct activation apparently has a high threshold, because it required strong electric fields to be elicited. The high threshold made it difficult to record this response, due to episodes of spreading depression triggered by the high stimulus amplitude (Okada et al., 1988a). For the same reason, it was very difficult to record an MEF in response to this phase because the need to average over 100 epochs would favor episodes of spreading depression. It should be noted that dendritic calcium spikes (Chan et al., 1988) were also observed that were insensitive to KYNA. These spikes might be responsible for the component that survived the bath application of KYNA, but not $\mathrm{Mn}^{2+}$, in the EP. This possibility, however, requires verification.

The use of MEF has a dual purpose in this study. First, it served as a measure of population responses, as pointed out above. From this point of view, the MEF provided the information about the direction of the underlying currents, complementing such notion obtained by the CSD analysis of the EP. Second, this study provided the characteristics of the magnetic field that may be associated with various types of currents produced by neurons. We found that an MEF on the order of $1 \mathrm{pT}$ at a measuring distance of $2 \mathrm{~cm}$ could be produced by a tissue with a surface area of about $20 \mathrm{~mm}^{3}$, due to changes in $\mathrm{Na}^{+}$ conductance and also to changes in membrane conductance produced by excitatory synaptic inputs (mostly carried by $\mathrm{Ca}^{2+}$ conductance changes as shown by the characteristic wave form of the TMP for $\mathrm{Ca}^{2+}$ currents). This ratio of $0.2 \mathrm{pT} / \mathrm{mm}^{3}$ is on the same order of magnitude as those estimated for the MEF that could be elicited by a peduncular stimulation or by stimulation of the dorsal surface of the cerebellum (Okada et al., 1989).
The present results may be useful in understanding effects of the electric and magnetic stimulations of the brain that are becoming more commonly used in clinical research (Amassian et al., 1987; Grandori and Rossini, 1988). The effectiveness of these remote stimulations of the brain is due to the electric field in the brain tissue that is induced directly by the extracranially applied electric field or indirectly by the magnetic field that produces eddy currents in the brain. The present results, together with the related studies of the physiological effects of applied electric field (Ranck, 1975; Chan and Nicholson, 1986; Tranchina and Nicholson, 1986; Chan et al., 1989), provide a further step in understanding the depolarization and hyperpolarization and hence the conductance changes induced by an applied electric field.

\section{References}

Amassian VE, Stewart M, Quirk GJ, Rosenthal JL (1987) Physiological basis of motor effects of a transient stimulus to cerebral cortex. Neurosurgery 20:74-93.

Chan CY, Nicholson C (1986) Modulation by applied electric field of Purkinje and stellate cell activity in the isolated cerebellum. J Physiol (Lond) 371:89-114.

Chan CY, Hounsgaard J, Nicholson C (1988) Effects of electric fields on transmembrane potential and excitability of turtle cerebellar Purkinje cells in vitro. J Physiol (Lond) 402:751-771.

Chan CY, Hounsgaard J, Mitgaard J (1989) Excitatory synaptic responses in turtle cerebellar Purkinje cells. J Physiol (Lond) 409:143156.

Chesler M, Chan CY (1988) Stimulus-induced extracellular pH transients in the in vitro turtle cerebellum. Neuroscience 27:941-948.

Cochran SL (1983) Kynurenic acid: competitive agonist of excitatory synaptic transmission? Neurosci Lett [Suppl] 40:S68.

Grandori F, Rossini P (1988) Electrical stimulation of the motor cortex: theoretical considerations. Ann Biomed Eng 16:639-652.

Hounsgaard J, Midtgaard J (1988) Intrinsic determinants of firing pattern in turtle Purkinje cells of the turtle cerebellum in vitro. $\mathrm{J}$ Physiol (Lond) 403:731-749.

Hounsgaard J, Midtgaard J (1989) Synaptic control of excitability in turtle cerebellar Purkinje cells. J Physiol (Lond) 409:157-170.

Künzle H (1985) Climbing fiber projection to the turtle cerebellum: 
longitudinally oriented terminal zones within the basal third of the molecular layer. Neuroscience 14:159-168.

Larson-Prior LJ, McCrimmon DR, Slater T (1990) Slow excitatory amino acid receptor-mediated synaptic transmission in turtle cerebellar Purkinje cells. J Neurophysiol 63:637-650.

Llinás R, Nicholson C (1971) Electrophysiological properties of dendrites and somata in alligator Purkinje cells. J Neurophysiol 34:532551.

Llinás R, Sugimori M (1980a) Electrophysiological properties of in vitro Purkinje cell somata in mammalian cerebellar slices. J Physiol (Lond) 305:171-195.

Llinás R, Sugimori M (1980b) Electrophysiological properties of in vitro Purkinje cell dendrites in mammalian cerebellar slices. J Physiol (Lond) 305:197-213.

Lopez L, Chan CY, Okada YC, Nicholson C (1989) Transmembranc potential, extracellular and magnetic evoked field in response to applied electric field in the isolated turtle cerebellum. Soc Neurosci Abstr $15: 1237$.

Lorente de Nó R (1947) Action potential of the motoneurons of the hypoglossus nucleus. J Cell Comp Physiol 29:207-287.

Mitzdorf U (1985) Current source-density method and application in cat cerebral cortex: investigation of evoked potentials and EEG phenomena. Physiol Rev 65:37-100.

Nicholson C (1980) Modulation of extracellular calcium and its functional implications. Fed Proc 39:1519-1523.

Nicholson C, Freeman JA (1975) Theory of current source-density analysis and determination of conductivity tensor for anuran cerebellum. J Neurophysiol 38:356-368.
Okada YC (1989) Recent developments on the physiological basis of magnetoencephalography (MEG). In: Advances in biomagnetism (Williamson SJ, eds), pp 273-278. New York: Plenum.

Okada YC, Nicholson C (1988) Magnetic evoked ficld associated with transcortical currents in turtle cerebellum. Biophys J 53:723-731.

Okada YC, Lauritzen M, Nicholson C (1988a) Magnetic field associated with spreading depression: a model for the detection of migraine. Brain Res 442:185-190.

Okada YC, Lopez L, Nicholson C (1988b) Origin of the magnetic evoked field produced by applied electric field in the isolated turtle cerebellum. Soc Neurosci Abstr 14:340.

Okada YC, Nicholson C, Llinás R (1989) Magnetocncephalography (MEG) as a new tool for non-invasive real time analysis of norma and abnormal brain activity in humans. In: Visualization of brain function (Ottoson D, Ottoson RW, cds), pp 245-266. Ncw York: Stockton.

Ranck JB Jr (1975) Which elements are excited in electrical stimulation of mammalian central nervous system: a review. Brain Res 98 : $417-440$.

Tranchina D, Nicholson C (1986) A model for the polarization of neurons by extrinsically applied electric fields. Biophys J 50:11391156.

Wikswo JP Jr, Palmer JO, Barach JP (1981) Magnetic measurements of action currents in single isolated nerve axons. Bull Am Physiol Soc 26:1223, 